\title{
The Politics of Renewable Energy Production in a Federal Context: The Deployment of Small Hydropower in the Swiss Cantons
}

\author{
Isabelle Stadelmann-Steffen \\ Stefan Rieder \\ Chantal Strotz \\ University of Bern \\ Interface, Lucerne \\ Interface, Lucerne \\ Isabelle.stadelmann@ipw.unibe.ch \\ rieder@interface-pol.ch \\ strotz@interface-pol.ch
}

This is a post-peer-review, pre-copyedit version of an article published in Journal of Environment and Development - please cite as Stadelmann-Steffen, I., Rieder, S., \& Strotz,

C. (2020). The Politics of Renewable Energy Production in a Federal Context: The Deployment of Small Hydropower in the Swiss Cantons. The Journal of Environment \& Development, 29(1), 75-98. https://doi.org/10.1177/1070496519886005

\begin{abstract}
Acknowledgment: The research presented in this article was funded by the Swiss National Science Foundation within the framework of the National Research Program (NRP) 71 «Managing Energy Consumption». We thank Andreas Balthasar, Frédéric Varone, Miranda Schreurs and the participants of the workshop "Federalism and Energiewende: Germany, Switzerland, and California/the United States" in Burghausen, October 2018, for helpful comments on earlier versions of this article as well as Ana Petrova for linguistic assistance.
\end{abstract}




\begin{abstract}
This article explores the factors that hinder and promote the deployment of renewable energy generating infrastructure in/across the Swiss cantons (i.e. the country's federal units). Using the example of small-scale hydropower, we shed light on how political regulations at the cantonal level interact with national policies and the local political process to affect the deployment of renewable energy production. The analysis demonstrates that political regulations can both foster and hinder the deployment of renewable energy production. While the national feed-in tariff scheme is revealed to be a beneficial framework condition, cantonal regulations hamper, rather than facilitate, the deployment of small-scale hydropower. Moreover, inclusive local processes and the existence of local entrepreneurs seem to act as a trigger for the local acceptance of renewable energy generation infrastructure. More generally, we conclude that, quite independently of whether state structures are decentralized or centralized, subnational and local leeway in the definition and organization of projects can help to prevent or deal with local opposition.
\end{abstract}




\section{Introduction}

Renewable energy production is on the rise in many countries. This trend is a reflection of the fact that by 2016, almost all states had formulated political goals to increase their share of renewable energies (REN21 2017). Many countries have adopted explicit policies aimed at promoting renewable energy production, such as feed-in-tariffs, tendering or fiscal incentives (REN21 2017) targeted at both “old” (e.g., hydropower) and "new" (wind and solar power) renewable energy technologies (RET). Yet, the implementation of these political goals and policies which requires the construction of renewable energy generation infrastructure, tends to trigger opposition (Devine-Wright 2011; Soini et al. 2011; Wüstenhagen, Wolsink, and Bürer 2007). This can result in the delay or even termination of local projects.

The present contribution focuses on the difficulties related to the implementation of RET infrastructure in a federal context and asks: What factors promote and obstruct RET implementation at the local level? Using the deployment of small-scale hydropower in the Swiss cantons as an example, we depart from the assumption that the prevalence of renewable energy production is not the exclusive result of natural, technical and economic aspects. Instead, we argue that renewable energy development is decisively influenced by political factors. We are particularly interested in how the cantonal policy mix shapes RET implementation. The study seeks to shed light on how the cantonal policy context interacts with political regulations at the national level and local political processes to affect the deployment of renewable energy production. The role of three different political levels (national, cantonal, and local) is highly relevant for RET implementation, which eventually takes place at the local level but is also heavily influenced by political regulations at higher administrative levels (see Lachapelle, Borick, and Rabe 2012) - particularly in federal countries like Austria, Belgium, Canada, Germany, Switzerland and the United States. These aspects of multi-level governance and the importance of local processes and stakeholders have been overlooked in previous research on 
renewable energy policies and implementation (Valentine 2010, 1918). Focusing on Switzerland, where the national level has set comparatively ambitious goals concerning the promotion of renewable energy production (see Balthasar, Schreurs \& Varone, this issue), our study aims to identify the factors that are conducive to the successful local implementation of national targets in a context of ample subnational autonomy.

Switzerland is a particularly apt choice for a systematic comparison. Whereas most previous studies in the field have focused on either a single or small number of political entities (see Tabi and Wüstenhagen 2017 for a literature review), we use a (subnational) comparative perspective to identify factors that generally tend to facilitate or hinder the deployment of renewable energy production.

Empirically, we focus on small-scale hydropower (facilities with a mean mechanical gross capacity of $0.3 \mathrm{MW}$ up to $10 \mathrm{MW}$ ), for which reliable cantonal deployment data are available. The Swiss Energy Strategy 2050 identifies small-scale hydropower as one renewable energy source that should be promoted in order to replace the current energy production from nuclear plants. A recent report assessing the potential of small-scale hydropower in Switzerland concludes that with $0.7-2.0$ TWh the potential for new small-scale hydropower plants is "relatively small, but non-negligible" (Bauer et al. 2017, 30). While compared to other RET like wind or solar power, small-scale hydropower may be most strongly restricted by natural factors such as the existence of waterways and topography, the implementation of small-scale hydropower projects is characterized by environmental, economic, and societal conflicts similar to those relevant to the implementation of RET in general (Tabi and Wüstenhagen 2017, 763). Generating new insights into the factors that influence the deployment of small-scale hydropower can therefore inform RET implementation more broadly.

We apply a mixed-methods approach, and combine a statistical comparison of the Swiss cantons based on a Bayesian estimation approach with qualitative comparative case studies. 
Whereas the quantitative approach enables us to analyze generalizable patterns associated with the deployment of small-scale hydropower, namely the role of varying cantonal policy contexts, the qualitative analysis provides a more in-depth understanding of the mechanisms behind these generalizable factors, as well as of the interactions among local, cantonal, and national factors.

The remainder of this article is structured as follows. First, we provide a short overview of the different degrees of deployment of small-scale hydropower in the Swiss cantons. In the next section, a theoretical background and hypotheses, which could explain this variation, are presented. This is followed by a discussion of our data, methods and empirical results. The Swiss findings are also presented in a comparative perspective. We conclude with a summary of our most important findings and a discussion of their implications.

\section{Small-scale Hydropower in the Swiss Cantons}

Hydropower is Switzerland's most important source of renewable energy. In 2018, it accounted for 57 percent of total electricity production (Bundesamt für Energie BFE 2018). Electricity production from small-scale hydropower has a long tradition. The number of small-scale hydropower plants has increased from 300 with an installed capacity of around $700 \mathrm{MW}$ in 1990 to 470 and an installed capacity of 940 MW in 2017 (Bundesamt für Energie BFE 2017). To reach the production goals defined in the national Energy Strategy 2050, the country needs to both update and expand existing power plants and build new ones.

The deployment of hydropower requires different policy measures. Switzerland's federal structures strongly shape energy policy. While the federal level defines the general energy strategy based on framework legislation and programs, the cantons are responsible for its implementation (Rieder, Balthasar, and Kissling-Näf 2014; Sager 2014). As a result, cantons enjoy considerable leeway in policy design. They can decide how strongly and through what instruments renewable energy policies will be promoted, which, in turn, results in a large 
cantonal heterogeneity not only in terms of the adopted energy policies but also with regards to the deployment of renewable energy infrastructure (Stadelmann-Steffen et al. 2018).

Figure 1 shows that small-scale hydropower plants exist in all Swiss cantons except Basel City. Yet, the number of power plants and the installed capacity differ greatly across cantons. For example, the cantons of Grisons, Valais, and Berne exhibit the highest number of power plants and the highest amount of installed capacity. In contrast, other large cantons like Zurich or Solothurn are marked by a significantly lower deployment of small-scale hydropower facilities.

--- Figure 1 about here ---

The bottom graph in Figure 1 depicts the usage rate in each canton, i.e., the installed capacity in relation to the federal unit's theoretical hydro-electrical potential (Schröder, Hemund, and Weingartner 2012). One can observe that the cantons differ in terms of the degree to which they exploit their natural potential. For example, installed capacity only corresponds to $6 \%$ of Grison's theoretical potential in small-scale hydropower, whereas in Berne this share is twice as high. The remainder of this paper seeks to explain these differences both theoretically and empirically.

\section{Theoretical Background: Promoters of and Barriers to the Deployment of Renewable Energy Sources in a Federal Context}

The previous literature on RET implementation suggests that successful implementation relies on a wide range of different factors. While natural and economic factors, such as the availability of technical solutions and the presence of natural and economic preconditions, obviously play an important role, the "social side" (Batel, Devine-Wright, and Tangeland 2013) of RET implementation can not be ignored. A lack of social acceptance is "one factor that can 
potentially be a powerful barrier to the achievement of renewable energy targets" (Wüstenhagen, Wolsink, and Bürer 2007, 2683). We distinguish between two groups of explanatory factors to account for cantonal diversity in the deployment of small-scale hydropower: natural and economic factors, and (socio-)political factors. This distinction also reflects the main arguments in the existing hydropower debate, according to which hydropower plants should be assessed based on their specific costs and benefits? (Koch 2002).

Each canton's natural potential for small-scale hydropower is the most obvious of all natural and economic factors. The mountainous cantons Berne, Grisons, Ticino, Uri and Valais exhibit the highest theoretical potentials (Schröder, Hemund, and Weingartner 2012, 45). Political units with a high potential for small-scale hydropower may be expected to have a higher number of plants and a higher installed capacity. Yet, while natural potential captures what is technically feasible, it does not reflect the efficacy and efficiency aspects that installation rates are also dependent upon (e.g., a larger potential may make a plant more economically attractive, see also Koch (2002)).

On the technical side, local and regional companies that possess the know-how to plan and construct small-scale hydropower plants can be an important driver of their regional deployment. Previous experiences with RET increases the likelihood that their use will be expanded and reduces the likelihood of local opposition (e.g., Ek 2005; Firestone et al. 2012; Warren and Gastil 2015; Wolsink 2007). Accordingly, experience in the planning and construction of small-scale hydropower plants will arguably be related to lower construction costs driven by learning effects as well as R\&D (Kammermann 2018; Papineau 2006). Such conditions will be conducive to the deployment of small-scale hydropower. Finally, in the context of increasing electricity production from renewable sources, the question of how the generated electricity is integrated into the grid is crucial (e.g., Devine-Wright 2005; Osmani et al. 2013). This consideration may be particularly relevant in the case of small-scale hydropower 
plants, which are often found in rather remote or at least decentralized areas. Hence, if distribution grid operators offer easy access for decentrally produced electricity, small-scale hydropower plants are more likely to be built. The distribution grid operators in Switzerland are monopolies in their areas, and are obliged to purchase the produced electricity, provide the technical prerequisites to integrate the electricity into the grid (e.g., lines, transformers), and administratively and financially render accounts for the feed-in (e.g., register the amount of electricity and payments). However, whereas in some cantons, one distribution grid operator covers the entire cantonal area and, thus, all potential sites for a new plant, in other cantons the area and, for example, relevant river basins, are distributed among various operators. Not all distribution grid operators may be equally interested in connecting new power plants to the grid. Some operators will support the construction of a new plant or even initiate one themselves. Others may not find connecting a new power plant to the grid profitable, as such an operation may require that the grid be improved. In similar situations, one strategy to avoid costs is to provide unfavorable conditions so that project initiators eventually refrain from constructing a new power plant. This can be accomplished, for example, by raising connection $\operatorname{costs}^{1}$ or prolonging implementation processes. Hence, a higher number of distribution grid operators increases the likelihood that at least one distribution grid operator supports new projects or even initiates them.

Based on these considerations, we formulate three hypotheses about the role of natural and economic factors in the cantonal deployment of small-scale hydropower:

H1: The higher the natural potential of a canton is, the higher the deployment of small-scale hydropower will be.

H2: The more extensive the local know-how in terms of companies with experience and technical knowledge is, the higher the deployment of small-scale hydropower in the canton will be. 
H3: Good feed-in conditions in a canton are associated with a greater generation of smallscale hydropower.

As (socio-)political factors may also play an important role in RET implementation and the deployment of small-scale hydropower, we examine political factors at the subnational (here: cantonal) level. Although federal countries like Switzerland choose their framework legislation at the national level (which, thus, defines the general framework for all subnational units), federal units enjoy considerable leeway in how they steer cantonal energy production toward the nationally set targets. The particular policy mix that a canton adopts to promote hydropower may therefore help explain its deployment of small-scale hydropower. We expect a more encompassing policy mix, including both "soft instruments" like information and voluntary measures and financial or even regulatory instruments aimed at promoting hydropower plants, to be associated with more significant deployment of small-scale hydropower.

Moreover, implementation research has argued that cantonal administrative resources heavily affect the implementation of public polices (Rieder, Balthasar, and Kissling-Näf 2014; Sabatier and Mazmanian 1980). Rieder et al. (2014) have shown that, it the Swiss case, a lack of financial or personal resources in the administration and, particularly, in the responsible office is associated with implementation deficits as well as structural deficits in the implementation process. More specifically, these earlier findings lead us to expect that when the cantonal energy office has access to better and more copious administrative resources, the implementation of nationally formulated targets may be better and the deployment of small-scale hydropower may be higher.

Finally, previous research has emphasized that the lack of social acceptance of small-scale hydropower may act as a barrier to successful RET implementation (Dermont et al. 2017; Wüstenhagen, Wolsink, and Bürer 2007). In this vein, Dermont et al. (2017) argue that the different stages of the policy-making process need different types of social acceptance. High 
acceptance at the most general, socio-political level, will not automatically translate into local acceptance of concrete projects. Nevertheless, a high level of socio-political acceptance of small-scale hydropower can be expected to be conducive to a higher deployment of this renewable energy source because more concrete opposition towards specific local projects is less likely to develop during the implementation process.

Thus, political dynamics at the cantonal level lead us to expect that:

H4: More encompassing cantonal policies promoting hydropower are associated with a higher deployment of small-scale hydropower in the respective canton.

H5: Higher administrative resources at the cantonal level are associated with a higher deployment of small-scale hydropower.

H6: A high level of social acceptance of small-scale hydropower is conducive to a higher cantonal deployment of this energy source.

\section{Research Design}

\section{Method}

Methodologically, we combine a statistical comparison of the Swiss cantons with in-depth case studies of two cantons. The statistical analysis focuses on the cantonal level and helps identify the main factors associated with the deployment of small-scale hydropower in a generalizable way. In contrast, the case studies shed light on concrete local projects within two cantons and enable us to show how the statistical relationships and the underlying causal mechanisms work. They also clarify under what conditions national regulations like the feed-in tariff system are a prerequisite for successful (cantonal) projects and how much local aspects, such as the inclusion of local stakeholders, influence the planning and implementation process. 
We estimate cross-sectional Bayesian regression models in the first part of our analysis. The Bayesian approach is particularly suitable when the number of cases is low and when the data used cannot be considered a sample of some larger population (Jackman 2009). We analyze the full population by taking all 26 Swiss cantons (Jackman 2009) (although we exclude some of them in our main models, see below). The Bayesian approach provides a coherent basis for inference in our analysis of the distribution of small hydropower across the Swiss cantons.

In order to facilitate the interpretation of the Bayesian estimation results, we provide the mean and the $95 \%$ credible intervals of the posterior distribution, which can be interpreted like their counterparts produced by standard regressions. The mean is the average effect of an independent variable on the dependent variable and the credible interval gives a sense of the statistical reliability of the estimate. A full Bayesian analysis requires the specification of priors for the unknown parameters. We used non-informative priors for the coefficient parameters in order to affect the resulting posterior distribution as little as possible (Stegmueller 2013). We used the R package MCMCglmm (Hadfield 2010) to estimate the models. We let the models run for 800,000 iterations, with a burn-in of 600,000 and a thinning of 1 . Extensive diagnostics based on the graphical inspection of the trajectories and the autocorrelations as well as on Geweke and Heidelberg diagnostics indicate that the chains have mixed well and converged.

In the second part of our analysis, we explore two specific cases in order to gain a better understanding of the causal relationship between the independent and the dependent variables. The case study focuses on two similar projects in two different cantons: a project on the Walibach in the Grafschaft municipality in Valais, and a project on the Milibach in the Grindelwald municipality in Berne. The selection of the cases is based on the most similar systems design, using Mill's method of difference (Mill 1843; Teune and Przeworski 1970). Valais and Berne have similar natural potential for small-scale hydropower (Schröder, Hemund, and Weingartner 2012) and a high number of existing small-scale hydropower plants. 
Moreover, both cantons promote hydropower intensively (Kammermann 2018). Local environmental associations opposed both projects early on voicing concerns about nature and landscape protection. While the project in Valais was eventually successfully implemented, the Bernese project failed. We conducted expert interviews with both proponents of and opponents to the two projects (see Table 1) in an effort to identify the effect of both national factors, such as feed-in tariffs, and local factors, like the inclusion of local stakeholders, in explaining these different outcomes.

-- Table 1 about here --

\section{Variables and measurement used in the Bayesian analysis}

We rely on two indicators to measure the deployment of small-scale hydropower in the Swiss cantons. First, we measure how many small-scale hydropower plants existed in a canton (during the reference year of 2017). Then we capture the total installed capacity in the same year (in MW). The Federal Office of Energy (Bundesamt für Energie BFE 2017) provided the official data. Whereas the number of power plants reflects how successful a canton is in carrying out concrete projects, and thus also involves a procedural evaluation, our second variable is more outcome-oriented.

To operationalize the natural and economic factors discussed above we rely on three indicators. We use data on the theoretical useable small-scale hydro-electrical potential (in MW and excluding the lower courses of the large rivers Rhine and Rhone) provided by the Federal Office of Energy to capture natural potential (Schröder, Hemund, and Weingartner 2012, 45). We rely on the cantonal small-scale hydropower industry — namely on the number of firms that supply small-scale hydropower plants - to measure the local know-how on small-scale hydropower plant construction. Thirdly, we capture feed-in conditions with the number of distribution grid operators in each canton. 
Three indicators capture the aforementioned (socio-)political factors. First, Kammermann's (2018) index of the comprehensiveness of the existing cantonal policy mix operationalizes each canton's intensity of hydropower promotion. Kammermann (2018) assigned all 26 cantons to four categories based on the hydropower policy adopted by each federal unit. Cantons with a strong hydropower strategy containing multiple coordinated instruments received the value of 1. Cantons with multiple instruments not as encompassing as an overall strategy were assigned a value of 0.67 . Those with soft instruments only (e.g., information) received the value of 0.33 , and those with no instruments promoting hydro-electricity were coded as 0 . Since only a few cantons fall into Kammermann's middle categories we recoded this indicator into a dummy variable whereby cantons with only soft instruments or no instruments whatsoever promoting hydropower received a value of 0 and those characterized by a full hydropower strategy or at least by multiple different instruments were assigned the value of 1 . We used the following measures to construct an index of administrative resources: number of full-time positions, personnel and material expenditures, and support contributions from the cantonal energy office (all indicators at the per capita level). We used the mean of the standardized values. Finally, we used survey data - the percentage of respondents who agree that small-scale hydropower should play a larger role in Switzerland's future energy mix - to measure the socio-political acceptance that small-scale hydropower enjoys in each canton (Stadelmann-Steffen and Dermont 2016).

We further controlled for each canton's financial situation as well as the share of left-green parties in parliament in the analysis. More information on the variables, their descriptive statistics, and the data sources used is available in the Appendix (Table A.1).

Our explanatory variables are lagged to the year before 2017 to measure potential causes before the observed actual outcomes (i.e., the deployment of small-scale hydropower 2017). However, strictly speaking, our cross-sectional design does not allow for causal conclusions. The small- 
scale hydropower plants in the Swiss cantons have experienced more or less continuous development over the last several decades. Thus, we acknowledge that the regression coefficients should be interpreted as associations rather than as causal effects, while the case studies help us shed light on the causality behind some of the statistical relationships the models make clear.

\section{Empirical results}

Figure 2 presents the results of the Bayesian regression analysis. In this model, we excluded the four cantons that have almost no small-scale hydropower potential: Appenzell Inner Rhodes, Appenzell Outer Rhodes, Basle-Town and Schaffhausen. Thus, the number of cases in the presented models is 22. Further analyses (included in the Appendix, Figure A.1) show that using the full sample leads to slightly larger credible intervals, whereas the main conclusions are the same as those described below.

The results for both dependent variables, namely the number of power plants and the installed capacity, are very similar. This is not surprising given that the correlation between the two variables is very high (Pearson's $r=0.96$ ). However, the two variables measure different aspects of the deployment of small-scale hydropower. The closeness of the results speaks for the validity of our measurement.

Not surprisingly, the natural potential of a canton is the most significant variable in the model. Thus, a larger natural potential for small-scale hydropower is associated with both a higher number of power plants and a higher total installed capacity. The number of distribution grid operators is positively associated with the deployment of small-scale hydropower. This finding is in keeping with the expectation that a higher number of distribution grid operators increases the likelihood that at least one of them will support or even initiate a project, and offer good feed-in conditions. 
In addition to these natural and economic factors, the cantonal policy context is also systematically related to the deployment of small-scale hydropower in the cantons. However, and against our expectations, the more encompassing the cantonal policy mix is in terms of its promotion of hydropower, the lower (rather than higher) the cantonal deployment of smallscale hydropower is. We will come back to this result later on in the paper.

While the remaining variables are not systematically associated with the number of small-scale hydropower plants or the installed capacity, it is worth mentioning that the socio-political acceptance of small-scale hydropower tends to be positively correlated with both dependent variables. However, in both cases the credible intervals are broad and contain zero (i.e., the coefficient is not systematically different from zero). Based on this result, we cannot conclude that higher acceptance levels are related to a higher deployment of this energy source. Naturally, this is also because our cross-sectional design does not allow for causal conclusions and because we cannot dismiss reverse causality. In fact, the deployment of small-scale hydropower could also influence the socio-political acceptance of this energy source in a given canton. In this vein, it is interesting to note that the estimation does suggest that the association between sociopolitical acceptance and hydropower deployment is very unlikely to be negative. Hence, we can basically reject the hypothesis that a sizable deployment of small-scale hydropower would decrease acceptance levels - a mechanism that could eventually be expected in light of the importance of factors such as the plants' impact on local landscape, people's closeness to a plant, or their attachment to the land on their opposition to RET infrastructures (e.g., DevineWright 2009; Hall, Ashworth, and Devine-Wright 2013). 
Our most intriguing finding is that an encompassing mix of policy instruments targeted at hydropower, which we expected to be conducive to a greater use of this energy source, is systematically and negatively associated with the presence of small-scale hydropower in a canton. To shed light on the mechanisms behind these findings, we present a comparative case study of one successful and one failed project in the cantons of Valais and Berne, respectively. Expert interviews identify three factors that were important for the success of the Valais project (Stadelmann-Steffen et al. 2018, 121). First, the economic conditions were favorable to this initiative. Specifically, the project was characterized by a solid profitability partly caused by the national feed-in tariff, which facilitated compensation payments. Moreover, because the municipality held a stake in the power plant, the municipality - and, thus, its citizens - could also financially profit from the project. Second, the Valais project proponents showed a strong willingness to engage in a dialogue with the local population and their opponents (NGOs), and actively sought a compromise. Meanwhile and relatedly, local entrepreneurs (the representatives of the municipality and of the electricity company) played an important role as promoters and mediators. As a result of these three factors, the initial opposition to the project was successfully addressed and faded away.

The Bernese case also included negotiations between the opponents and the proponents of the hydropower project. The main focus of the opposition had to do with the actual location of the proposed power plant but alternative places were not acceptable to the electricity company. The lack of an acceptable alternative and the persistent local opposition to the initial proposal led to the project's termination. The interviews with Bernese insiders consistently emphasized hydropower regulations. Berne has a water use strategy that stipulates the canton's general goals and principles with respect to the use of hydropower and serves as its central planning tool. The strategy also classifies all running waters into green, yellow and red zones. The green zone allows the use of hydropower and the yellow zone only allows it under certain conditions, 
while in the red zone the use of hydropower is not permitted. The interviewed actors explained that this positive planning had largely been responsible for the proposed location of the plant, which was planned to be in the green zone. Meanwhile, locations outside of the green areas, which might have been more advantageous from an economic or an efficacy perspective, were never considered because of the cantonal regulations in place. Valais also intensively promotes and regulates hydropower but does not apply positive planning, i.e., the definition of zones where hydropower use is allowed or prohibited. Moreover, regulation is much more decentralized in Valais than in Berne (Kammermann 2018), allowing local-level authorities more leeway in the planning and regulating of such processes.

The comparison of the two projects provides important insights into why an encompassing promotion of hydropower, characterized by both a mix of promotional instruments and the existence of a hydropower strategy, is negatively, rather than positively, associated with the deployment of small-scale hydropower. It is important to note that the policy indicator we used in the quantitative analyses focuses on instruments intended to promote hydropower. Besides subsidies and information, one such instrument is regulation aimed at reducing conflicts between renewable energy infrastructure and spatial planning. However, the case studies suggest that intense cantonal promotion and regulation can take different shapes and, accordingly, have different intended and unintended consequences. More precisely, cantonal policies can be dominated by a "promotion logic," like the Valais case illustrates. Regulation entails negative planning: the exploitation of some zones may be expressly forbidden, but specific zones for the use of hydropower are not explicitly delineated. In addition, when new plants are planned, areas with existing plants are preferred locations for the new projects as well. Regulation is decentralized and, thus, provides substantial autonomy to promoters of small-scale hydropower projects in terms of the design and organization of local projects. Such a policy context seems to be advantageous for the deployment of small-scale hydropower, especially when socio-political acceptance is high and economic conditions are good. 
Conversely, cantonal policies can also follow a "protection logic." Examples for this kind of regulation are the specification of something like "green" and "red" zones as in the case of Berne and, relatedly, a higher degree of centralization. This alternative type of intense regulation may also target the promotion of hydropower, but in reality and due to a reduction in flexibility at the local/project level, tends to obstruct successful implementation. ${ }^{2}$

\section{Discussion: The Swiss Case in International Comparison}

The analysis presented in this article is one of the first to systematically analyze RET implementation within federations, as Lachapelle et al. (2012) suggested be done. In this section, we proceed to put our findings in an international comparative perspective, i.e., "across federal systems" (Lachapelle, Borick, and Rabe 2012, 354). One challenge to this effort is the fact that federal states do not form a homogeneous group. Not only do they vary with respect to the specific power allocation in place between state levels (especially in the energy sector), but they also differ in terms of the surrounding political context, their energy-related goals, and their promoters. Although these specificities make generalization a difficult if not impossible task, we argue that our results point to at least two notable findings, especially compared to previous research from Canada, Germany, and the United States, but also in view of the other contributions to this special issue:

Taking local processes and factors into account: Our analysis shows that very specific local or regional factors and processes and, relatedly local acceptance affect the deployment of RET infrastructure. We emphasize the role of local entrepreneurs who promote such projects but also act as mediators in cases of conflict. It is reasonable to expect that these conclusions are applicable to other federal systems, where multi-level structures provide incentives and opportunities for such local dynamics to unfold. However, the mechanisms behind these dynamics and, thus, the interaction between policies at the different state levels may vary. In 
Switzerland, it is the national level that has set very ambitious energy-related goals. Subnational and local governments must basically comply with these national targets. This relationship differs quite markedly from the one in countries like Canada or the United States, where "the absence of federal regulations on GHG emissions has left a policy vacuum for sub-federal governments to fill" (Lachapelle, Borick, and Rabe 2012, 345) and where, therefore, the transition of the energy system is driven by forerunner subnational entities (see Mazmanian et al. in this special issue). In such a context, local entrepreneurs and local acceptance may be even more important for the successful implementation of RET (see e.g., Walker and Baxter 2017b, 2017a).

The chances of decentralization: Decentralized federal structures - thought to present an additional veto point in the political systems (Tsebelis 2002) - have been considered a hurdle for the transition of energy systems in general and RET implementation in particular (Valentine 2010). Valentine $(2010,1921)$ hypothesizes that in Canada, more central structures would facilitate the implementation of coercive instruments to both promote renewable energy and better coordinate among, for example, provinces with either high hydropower or high wind power potentials. Germany might serve as the prime example of a centralized (and federal) country that has been a front runner in the deployment of renewable energies (Weidner and Mez 2008). The federal level also concentrates authority for all regulatory issues related to power lines in order to increase efficiency and to reduce bureaucracy (Steinbach 2013, 227). However, the construction of energy-related infrastructure (i.e., wind farms, grid extensions) has increasingly simultaneously provoked local opposition in the country (Quitzow et al. 2016, 166f.; Reusswig et al. 2016). Moreover, empirical evidence from other more centralized contexts (both unitary and federal) documents a more sceptic view of the effect of centralized structures on the promotion of renewables. Wolsink (1996) argues that "central planning problems" were important reasons why wind power was not successfully implemented in the Netherlands (see also Wolsink 2007 for a more recent corroboration of this claim). In the 
Australian federal system, the lack of coordination between the federal and the state governments served as a barrier to the development of renewable energies (Jones 2009). Together with these findings, the Swiss results suggest two conclusions. First, decentralized political structures do not necessarily hinder the deployment of RET. Naturally, if the national level is the "pusher" (Weidner and Mez 2008, 371) of renewable energy, the centralization of powers speeds up their development, but the opposite can happen if the national government serves as a "barrier" to change, like in the United States under Donald Trump or Canada under Stephan Harper. In the latter cases, decentralized structures where subnational units can "push" for change may be advantageous. These forerunners may trigger diffusion and learning effects (Berry and Berry 2014; Braun and Gilardi 2006), and thus encourage other subnational units to follow their lead in a bottom-up fashion. The comparison of Germany and Switzerland - both countries with ambitious national targets - also reveals that centralized powers do not prevent local protest from emerging. Indeed, subnational autonomy and practices of multi-level governance, like in the Swiss case, help create locally adapted solutions that may facilitate successful RET implementation.

\section{Conclusion}

This article has explored the factors that obstruct and promote the deployment of renewable energy generating infrastructure in the Swiss federal units. Using the example of small-scale hydropower, we shed light on how political regulations at the cantonal level and the interaction between national policies and local political processes affect the deployment of renewable energy production. Relying on a mixed-method approach, we arrive at the following main findings.

First, while the deployment of small-scale hydropower is strongly associated with the respective areas' natural potential for the generation of this energy, the Swiss cantons vary in the extent to 
which they tap into their potential. This is a first indication that the Swiss subnational units use their leeway in implementing the nationally-set energy targets and they do so in varying ways. The statistical analysis suggests that this observed variety is explained by natural, economic, and political conditions. The number of distribution grid operators is positively correlated with the deployment of small-scale hydropower. This finding lends support to our hypothesis that where several such operators exist within a canton, the likelihood of at least one of them offering good feed-in conditions for planned projects or even initiating local projects increases. This result fits in well with a more general discussion about the challenge of feeding decentrally produced renewable-source electricity into the grid (e.g., Battaglini et al. 2009; Hammons 2008; Osmani et al. 2013). Our study indicates that grid integration not only concerns the system level, but may also influence actors' decisions and behavior with regards to electricity production at the project level.

Moreover, our analysis implies that policies both at the national and the subnational level play a role in the deployment of small-scale hydropower. This said, while national policies obviously cannot account for the variation in deployment levels across the cantons, the case study of Valais demonstrates that the national feed-in tariff system affects projects' economic conditions. National subsidies can have two effects. On the one hand, they can help find a compromise with local-level opposition by providing compensation payments. On the other hand, the resources may also enable initiators to optimize the quality of a project. At the subnational level, the varying degrees to which cantons promote and regulate (small-scale) hydropower are related to the cantonal deployment of small-scale hydropower. However, although we expected that having an encompassing policy mix in place to promote hydropower would be correlated with a more sizable deployment of small-scale hydropower, our quantitative analyses produced the opposite results. The Valais and Berne case studies show that the regulation logic in place is more important than the question of how encompassing the 
cantonal policy mix is. In particular, regulation following a "protection logic," which involves positive planning and centralized structures, can trigger a restrictive effect on the deployment of small-scale hydropower by excluding viable alternatives and reducing the ability to react to local demands in a flexible way.

Furthermore, our analysis corroborates previous research emphasizing the crucial role that social acceptance plays in RET implementation (e.g., Batel, Devine-Wright, and Tangeland 2013; Stadelmann-Steffen et al. 2018; Wüstenhagen, Wolsink, and Bürer 2007). Whereas the statistical analysis focused on the socio-political acceptance of small-scale hydropower and, thus, on the technology level, the case studies revealed that "community acceptance" (Wüstenhagen, Wolsink, and Bürer 2007) is crucial for successful implementation at the project level. As discussed above, advantageous technical and political conditions can help reduce or even dissolve local opposition. Open regulation and subsidies in particular increase actors' room for maneuver and, thus, the likelihood of finding an acceptable solution. However, at the end of the day, the local actors determine a projects' success or failure. The role of local entrepreneurs who act as project promoters and process mediators cannot be underestimated.

Naturally, our study is not without limitations. It focuses on one specific renewable energy source in a single country. For example, one might assume that the important role of planning policies identified in this study is peculiar to hydropower, which is particularly strongly restricted by the existence of waterways and topography, whereas it might be less important for, e.g., solar or wind power where siting alternatives might be more numerous. Future research should broaden the perspective and investigate on whether the factors identified in this study can be generalized to different energy sources and contexts. Still, we want to argue that the implications of our study are relevant beyond the Swiss case and beyond the case of small-scale hydropower. In particular, if decentralized energy sources are to be promoted, local actors (entrepreneurs) should be motivated and supported so that they consider initiating projects. 
Federal and subnational governments can provide advantageous conditions by defining general targets, providing incentives, and relying on open, non-restrictive regulation. This conclusion seems to be relevant regardless of state structures. In other words, subnational and local leeway in the definition and organization of projects can go a long way in successfully preventing or dealing with local opposition in countries with a centralized energy sector authority as well. 


\section{Notes}

\footnotetext{
${ }^{1}$ Some leeway exists with respect to connection costs, which are not fully determined in the feed-in tariff.

${ }^{2}$ Further case studies conducted within the framework of the project (in the cantons of Argovia and Grisons) support the conclusion that regulation open with respect to the siting of small-hydropower plants or the absence of regulation facilitates the deployment of this energy source (Stadelmann-Steffen et al. 2018). Unfortunately, the cantonal policy data used in the quantitative analyses do not allow for a distinction between different regulation logics.
}

\section{References}

Batel, S., Devine-Wright, P. \& Tangeland, T. (2013). Social acceptance of low carbon energy and associated infrastructures: A critical discussion. Energy Policy 58: 1-5.

Battaglini, A., Lilliestam, J. Haas, A. \& Patt, A. (2009). Development of SuperSmart Grids for a more efficient utilisation of electricity from renewable sources. Journal of Cleaner Production 17(10): 911-918.

Bauer, C., Erni, M., Saar, M. \& Tran, M.Q. (2017). Potentials, costs and environmental assessment of electricity generation technologies. Villigen PSI, Switzerland. https://www.psi.ch/lea/HomeEN/Final-Report-BFE-Project.pdf.

Berry, F.S. \& Berry, W. (2014). Innovation and diffusion models in policy research. In Sabatier, P.A. \& Weible, C.M. (Eds), Theories of the policy process (pp. 307-362). Boulder: Westview Press.

Braun, D., \& Gilardi, F. (2006). Taking ‘Galton's Problem' Seriously: Towards a Theory of Policy Diffusion. Journal of Theoretical Politics 18(3): 298-322.

Bundesamt für Energie BFE. (2017). Statistik der Wasserkraftanlagen der Schweiz. Stand 
1.1.2017. Retrieved July 5, 2017, from

http://www.bfe.admin.ch/themen/00490/00491/index.html?lang=de\&dossier_id=01049.

Bundesamt für Energie BFE. (2018). Hydropower.

http://www.bfe.admin.ch/themen/00490/00491/index.html?lang=en (August 28, 2018).

Dermont, C., Ingold, K., Kammermann, L. \& Stadelmann-Steffen, I. (2017). Bringing the policy making perspective in: A political science approach to social acceptance. Energy Policy 108: 359-368.

Devine-Wright, P. (2005). Beyond NIMBYism: Towards an integrated framework for understanding public perceptions of wind energy. Wind Energy 8(2): 125-139.

Devine-Wright, P. (2009). Rethinking NIMBYism: The role of Place Attachment and Place Identity in Explaining Place-Protective Action.” Journal of Community \& Applied Social Psychology 19(6): 426-441.

Devine-Wright, P. (2011). Enhancing local distinctiveness fosters public acceptance of tidal energy: A UK case study. Energy Policy 39(1): 83-93. http://dx.doi.org/10.1016/j.enpol.2010.09.012.

Ek, K. (2005). Public and private attitudes towards 'green' electricity: The case of Swedish wind power. Energy Policy 33(13): 1677-1689.

ElCom. 2014. Tarif-Rohdaten der schweizerischen Verteilnetzbetreiber. Retrieved March 9, 2015, from https:/www.elcom.admin.ch/elcom/de/home/themen/strompreise/tarifrohdaten-verteilnetzbetreiber.html.

Federal Council. (2005). Verordnung über die Festsetzung der Finanzkraft der Kantone für die Jahre 2006 und 2007. Retrieved March 9, 2015, from https://www.admin.ch/opc/de/classified-compilation/20052648/index.html\%0A.

Federal Statistical Office. 2016. Kantonale Parlamentswahlen. Retrieved April 14, 2016, from 
https://www.bfs.admin.ch/bfs/de/home/statistiken/politik/wahlen/kantonaleparlamenswahlen.html.

Firestone, J., Kempton, W., Blaydes Lilley, M. and Samoteskul, K. (2012). Public acceptance of offshore wind power across regions and through time. Journal of Environmental Planning and Management 55(10): 1369-1386.

Hadfield, J.D. (2010). MCMC methods for multi-response generalized linear mixed models: The MCMCglmm R Package. Journal of Statistical Software 33(2): 1-22.

Hall, N., Ashworth, P. and Devine-Wright, P. (2013). Societal acceptance of wind farms: Analysis of four common themes across Australian case studies. Energy Policy 58: 200208.

Hammons, T. J. (2008). Integrating renewable energy sources into European grids. International Journal of Electrical Power and Energy Systems 30(8): 462-475.

Jackman, S. (2009). Bayesian analysis for the social sciences. Chichester, Sussex: Wiley.

Jones, S. (2009). The future of renewable energy in Australia: A test for cooperative federalism? Australian Journal of Public Administration 68(1): 1-20.

Kammermann, L. (2018). Factors driving the promotion of hydroelectricity: A qualitative comparative analysis. Review of Policy Research 35(2): 213-237.

Koch, F. H. (2002). Hydropower-the politics of water and energy: Introduction and overview. Energy Policy 30(14): 1207-1213.

Lachapelle, E., Borick, C.P, \& Rabe, B. 2012. Public attitudes toward climate science and climate policy in federal systems: Canada and the United States compared. Review of Policy Research 29(3): 334-57.

Mill, J.S. (1843). A system of logic, ratiocinative and inductive. In Robson. J.M. (Ed.) (1973) Collected Works of John Stuart Mill, Vols. VII and VIII. Toronto: University of Toronto 
Press.

Osmani, A., Zhang J., Gonela, V. \& Awudu, I. (2013). Electricity generation from renewables in the United States: Resource potential, current usage, technical status, challenges, strategies, policies, and future directions. Renewable and Sustainable Energy Reviews 24: $454-472$.

Papineau, M. (2006). An economic perspective on experience curves and dynamic economies in renewable energy technologies. Energy Policy 34: 422-432.

Quitzow, L., Canzler, W., Grundmann, P., Leibenath, M., Moss, T. \& Rave, T (2016). The German Energiewende - What's happening? Introducing the special issue. Utilities Policy 41: 163-171.

REN21 (2017). Renewables 2017 global status report. Paris: REN21 Secretariat.

Reusswig, F., Braun, F., Heger, I., Ludewig, T., Eichenauer, E., \& Lass, W. (2016). Against the wind: Local opposition to the German Energiewende." Utilities Policy 41: 214-227.

Rieder, S., Balthasar, A., and Kissling-Näf, I. (2014). Vollzug und Wirkung öffentlicher Politiken. In Knoepfel, P., Papadopoulos Y., Sciarini, P., Vatter, A., \& Häusermann, S. (Eds.), Handbuch der schweizer Politik (pp. 563-598). Zürich: Neue Zürcher Zeitung,.

Sabatier, P., \& Mazmanian, D. (1980). The implementation of public policy: A framework of analysis. Policy Studies Journal 8(4): 538-560.

Sager, F. (2014). Infrastrukturpolitik: Verkehr, Energie und Telekommunikation. In Knoepfel, P., Papadopoulos Y., Sciarini, P., Vatter, A., \& Häusermann, S. (Eds.), Handbuch der schweizer Politik (pp. 721-748). Zürich: Neue Zürcher Zeitung.

Schröder, U., Hemund, C. \& Weingartner, R. (2012). Erhebung des Kleinwasserkraftpotentials der Schweiz Ermittlung des theoretischen Potentials und Methodik zu dessen ganzheitlicher Beurteilung. Bern. Retrieved March 9, 2017, from 
https://www.aramis.admin.ch/Default.aspx ?DocumentID=3499\&Load=true.

Schweizerische Energiedirektorenkonferenz (EnDK). (2015). Stand Der Energiepolitik in Den Kantonen. Bern.

Soini, K., Pouta, E., Samiovirta, M., Uusitalo, M., \& Kvinen, T. (2011). Local residents’ perceptions of energy landscape: the case of transmission lines. Land Use Policy 28(1): 294-305.

Stadelmann-Steffen, I, Ingold, K., Rieder, S., Dermont, C., Kammermann, L., \& Strotz, C. (2018). Akzeptanz erneuerbarer Energie. Universität Bern, Interface Politikstudien Forschung Beratung, EAWAG.

Stadelmann-Steffen, I. \& Dermont, C. (2016). Energie-Enquete 2016. Bern: Institut für Politikwissenschaft.

Stegmueller, D. (2013). How many countries for multilevel modeling? A comparison of frequentist and Bayesian approaches.” American Journal of Political Science 57(3): $748-761$.

Steinbach, A. (2013). Barriers and solutions for expansion of electricity grids-the German experience. Energy Policy 63: 224-229.

Swiss Small Hydro. 2014. Marktführer. Retrieved October 30, 2017, from https://marktfuehrer.swissmallhydro.ch/.

Tabi, A., \& Wüstenhagen, R. (2017). Keep it local and fish-friendly: Social acceptance of hydropower projects in Switzerland." Renewable and Sustainable Energy Reviews 68: $763-773$.

Teune, H., \& Przeworski, A. (1970). The logic of comparative social inquiry. New York: Wiley..

Tsebelis, G. (2002). Veto players: How political institutions work. Princeton: Princeton 
University Press.

Valentine, S.V. (2010). Canada's constitutional separation of (wind) power. Energy Policy 38(4): 1918-30.

Walker, C. \& Baxter. J. (2017a). It's easy to throw rocks at a corporation: Wind energy development and distributive justice in Canada." Journal of Environmental Policy and Planning 19(6): 754-68.

Walker, C. \& Baxter. J. (2017b). Procedural justice in Canadian wind energy development: A comparison of community-based and technocratic siting processes. Energy Research and Social Science 29: 160-169.

Warren, M.E. \& Gastil, J. (2015). Can deliberative minipublics address the cognitive challenges of democratic citizenship?” The Journal of Politics 77(2): 562-74.

Weidner, H. \& Mez, L. (2008). German climate change policy: A success story with some flaws. Journal of Environment and Development 17(4): 356-378.

Wolsink, M. (1996). Dutch wind power policy: Stagnating implementation of renewables. Energy Policy 24(12): 1079-1088.

Wolsink, M. (2007). Planning of renewables schemes: Deliberative and fair decision-making on landscape issues instead of reproachful accusations of non-cooperation. Energy Policy 35(5): 2692-2704.

Wüstenhagen, R., Wolsink, M. \& Bürer, M.J. (2007). Social acceptance of renewable energy innovation: An introduction to the concept. Energy Policy 35(5): 2683-2691. 


\section{Appendix}

Table A1: Variables used in the statistical analysis

\begin{tabular}{|c|c|c|}
\hline Variable & Descriptive statistics & Operationalization / Source \\
\hline $\begin{array}{l}\text { Number of small-scale } \\
\text { hydropower plants }\end{array}$ & $\begin{array}{l}\text { Mean: } 17.96 \\
\text { SD: } 21.92 \\
\text { Min: } 0 \\
\text { Max: } 85\end{array}$ & $\begin{array}{l}\text { Number of small-scale hydropower plants, } 2017 \\
\text { (Bundesamt für Energie BFE 2017) }\end{array}$ \\
\hline $\begin{array}{l}\text { Total installed capacity } \\
\text { in MW }\end{array}$ & $\begin{array}{l}\text { Mean: } 36.24 \\
\text { SD: } 48.05 \\
\text { Min: } 0 \\
\text { Max: } 190.73\end{array}$ & $\begin{array}{l}\text { Total installed capacity in MW, } 2017 \text { (Bundesamt für } \\
\text { Energie BFE 2017). In the regression analysis, we use } \\
\text { values in GW. }\end{array}$ \\
\hline Natural potential & $\begin{array}{l}\text { Mean: } 0.43 \\
\text { SD: } 0.77 \\
\text { Min: } 0.00 \\
\text { Max: } 2.95\end{array}$ & $\begin{array}{l}\text { Theoretical potential of small-scale hydropower in a } \\
\text { canton, in MW (Schröder, Hemund, and Weingartner } \\
\text { 2012). These are the data on which the figure on page } 45 \\
\text { is based. They are provided by the Federal Office of } \\
\text { Energy. In the regression analysis, we have used values in } \\
\text { GW. For the half-cantons, data contained the potential for } \\
\text { Basel-Country and Basle-Town as well as for the two } \\
\text { Appenzell together. We used the potential in GWh/a as } \\
\text { indicated in Appendix } 3 \text { of the aforementioned study to } \\
\text { calculate the amount for each half-canton. }\end{array}$ \\
\hline $\begin{array}{l}\text { Distribution grid } \\
\text { operators }\end{array}$ & $\begin{array}{l}\text { Mean: } 0.28 \\
\text { SD: } 0.35 \\
\text { Min: } 0.01 \\
\text { Max: } 1.11\end{array}$ & $\begin{array}{l}\text { Number of distribution grid operators (Elektrizitätswerke) } \\
\text { in each canton (in 100), } 2014 \text { (ElCom 2014). }\end{array}$ \\
\hline Hydropower industry & $\begin{array}{l}\text { Mean: } 2.08 \\
\text { SD: } 2.35 \\
\text { Min: } 0 \\
\text { Max: } 9\end{array}$ & $\begin{array}{l}\text { Number of companies supplying water turbines and small- } \\
\text { scale hydropower plants in each canton (Swiss Small } \\
\text { Hydro 2014). }\end{array}$ \\
\hline Cantonal policy mix & $\begin{array}{l}1=53.85 \% \\
0=46.15 \%\end{array}$ & $\begin{array}{l}\text { Index based on the existence of a hydropower strategy and } \\
\text { the instrument mix for the promotion of hydropower. } 1= \\
\text { encompassing strategy or instrument mix; } 0=\text { no strategy? } \\
\text { or only soft instruments. The data describes the cantonal } \\
\text { situation in } 2014 \text { (Kammermann 2018). }\end{array}$ \\
\hline Administrative resources & $\begin{array}{l}\text { Mean: }-0.00 \\
\text { SD: } 0.64 \\
\text { Min: }-0.81 \\
\text { Max: } 1.63\end{array}$ & $\begin{array}{l}\text { Mean of the standardized values of the following } \\
\text { indicators: Number of fulltime equivalents, personnel } \\
\text { costs, material expenditures and subsidies (per capita, } \\
\text { 2002-2014) (Schweizerische Energiedirektorenkonferenz } \\
\text { (EnDK) 2015). }\end{array}$ \\
\hline $\begin{array}{l}\text { Socio-political } \\
\text { acceptance }\end{array}$ & $\begin{array}{l}\text { Mean: } 0.62 \\
\text { SD: } 0.06 \\
\text { Min: } 0.50 \\
\text { Max: } 0.73\end{array}$ & $\begin{array}{l}\text { Share of respondents in } \% \text { per canton, who agree that } \\
\text { small-scale hydropower should be strengthened in the } \\
\text { future energy-mix in Switzerland. Data from } 2014 \\
\text { (Stadelmann-Steffen and Dermont 2016). }\end{array}$ \\
\hline $\begin{array}{l}\text { Cantonal financial } \\
\text { resources }\end{array}$ & $\begin{array}{l}\text { Mean: } 88.92 \\
\text { SD: } 46.33 \\
\text { Min: } 30.00 \\
\text { Max: } 224.00\end{array}$ & $\begin{array}{l}\text { Index based on the decree of the Federal Council regarding } \\
\text { the financial capacity of the cantons for the years } 2006 \text { and } \\
2007 \text { used for the definition of the financial compensation } \\
\text { scheme (Federal Council 2005). }\end{array}$ \\
\hline
\end{tabular}


Strength of left-green parties
Mean: 0.26

SD: 0.12

Min: 0.07

Max: 0.51
Share of green-left parties (SPS, GPS, GPS, GLP und small left-wing parties) in the cantonal parliament, 20022014 (Federal Statistical Office 2016). Missing value for the canton Appenzell Outer-Rhodes, where not all members of parliament can be assigned to a party.

Note: Based on the full sample (26 cantons).

Figure A1: Bayesian regression model of cantonal deployment of small-scale hydropower including the cantons with very low hydro-electrical potential

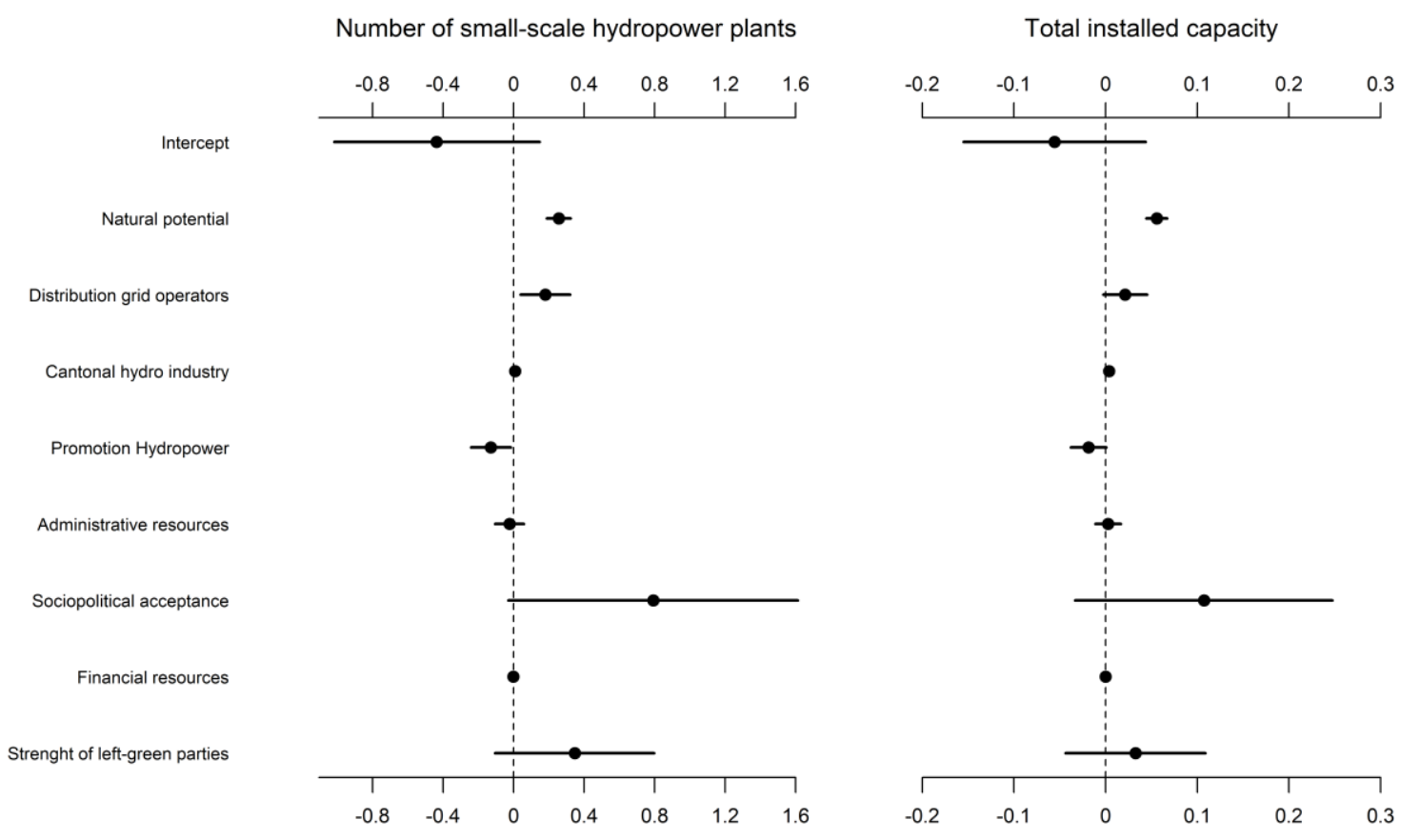

Notes: Bayesian linear regression (mean and the $95 \%$ credible interval), Bayesian estimation using the package MCMCglmm in R (Hadfield 2010). N = 25 (Appenzell Inner Rhodes could not be included, since no information on the share of left-green parties is available for this canton). 


\section{Tables and Figures}

Table 1: Interviewees

Case study: Walibach in Valais

- Grafschaft commune's president (Initiator of the project)

- Representative of the local electricity company EnBag (Initiator of the project

- Representative of WWF Haut-Valais (Opponent of the project)

\section{Case study: Milibach in Bern}

- Representative of the local electricity company BKW (the project was coinitiated by the EKW electricity company, which today is part of the BKW)

- Representative of the local association founded to oppose the project 
Figure 1: Deployment of small-scale hydropower in the Swiss cantons, 2017
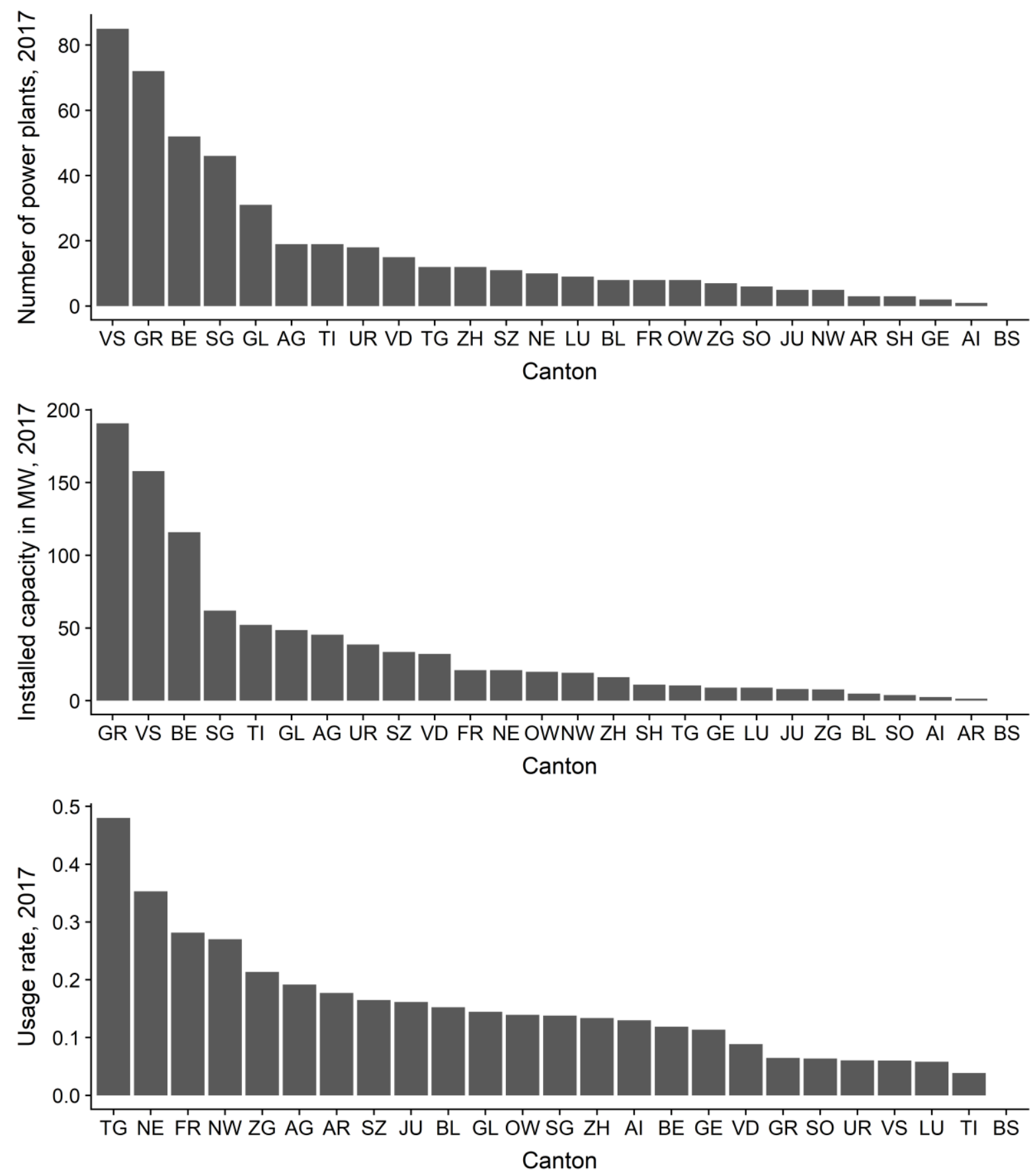

Source: Bundesamt für Energie BFE (2017), own illustration. Usage rate $=$ the installed capacity in relation to the theoretical hydro-electrical potential (Schröder, Hemund, and Weingartner 2012). The canton of Schaffhausen is excluded from the bottom graph, since its installed capacity exceeds the estimated theoretical potential, which excludes the lower course of the Rhine and the Rhone. 
Figure 2: Bayesian regression model of cantonal deployment of small-scale hydropower
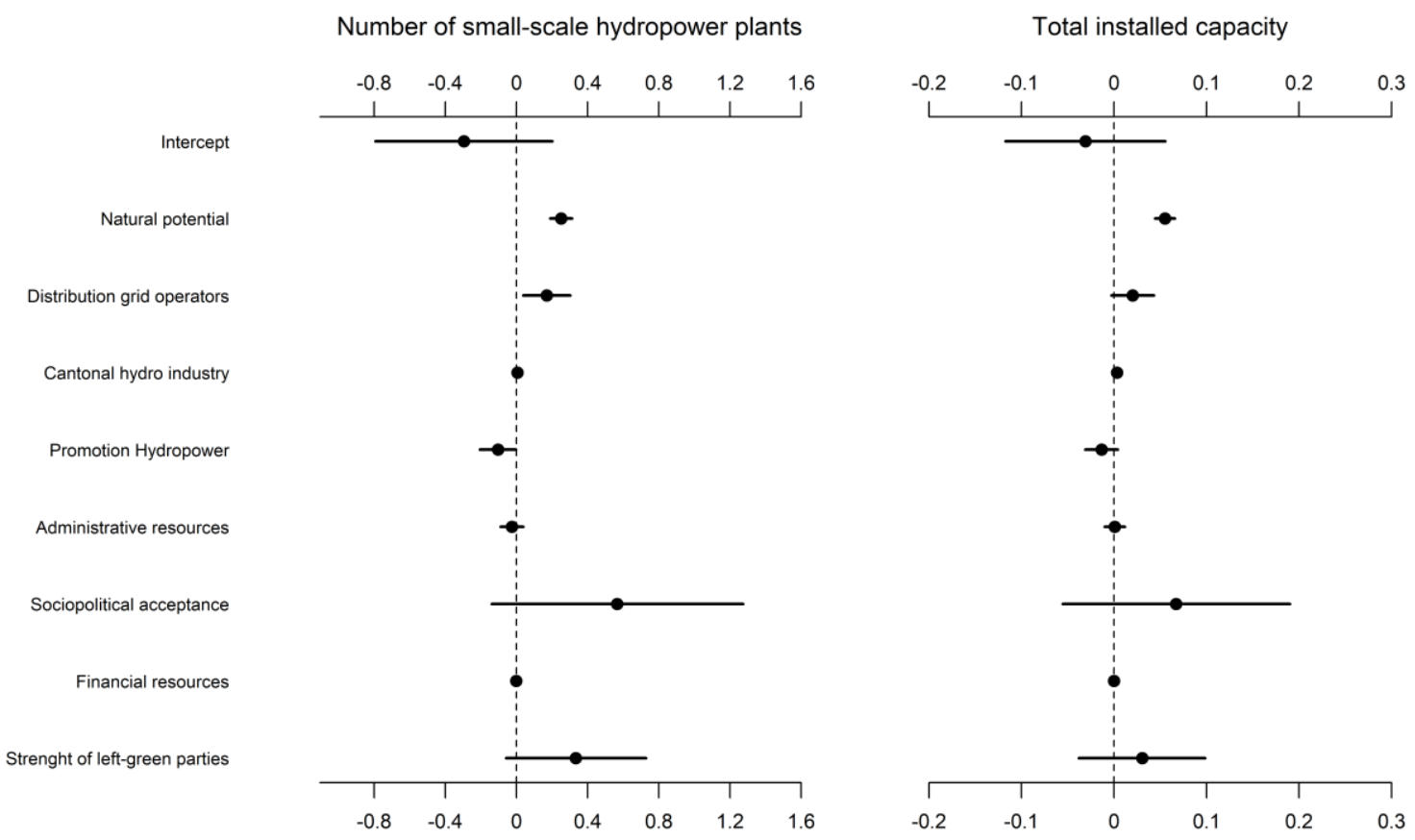

Notes: Bayesian linear regression (mean and the $95 \%$ credible interval), Bayesian estimation using the package MCMCglmm in R (Hadfield 2010). N = 22 (Four cantons with a hydro-electrical theoretical potential below $20 \mathrm{MW}$ are excluded: Appenzell Inner and Outer Rhodes, Schaffhausen, and Basel Town). 